\title{
Characterization of Corrosion Products on Carbon Steel Exposed to Natural Weathering and to Accelerated Corrosion Tests
}

\author{
Renato Altobelli Antunes, ${ }^{1}$ Rodrigo Uchida Ichikawa, ${ }^{2}$ \\ Luis Gallego Martinez, ${ }^{2}$ and Isolda Costa ${ }^{2}$ \\ ${ }^{1}$ Universidade Federal do ABC (UFABC), Centro de Engenharia, Modelagem e Ciências Sociais Aplicadas (CECS), \\ 09210580 Santo André, SP, Brazil \\ ${ }^{2}$ Instituto de Pesquisas Energéticas e Nucleares, IPEN/CNEN-SP, Avenida Professor Lineu Prestes 2242, \\ 05508-900 Cidade Universitária, SP, Brazil \\ Correspondence should be addressed to Renato Altobelli Antunes; renato.antunes@ufabc.edu.br
}

Received 30 December 2013; Revised 26 May 2014; Accepted 28 May 2014; Published 15 June 2014

Academic Editor: Jerzy A. Szpunar

Copyright (C) 2014 Renato Altobelli Antunes et al. This is an open access article distributed under the Creative Commons Attribution License, which permits unrestricted use, distribution, and reproduction in any medium, provided the original work is properly cited.

\begin{abstract}
The aim of this work was to compare the corrosion products formed on carbon steel plates submitted to atmospheric corrosion in urban and industrial atmospheres with those formed after accelerated corrosion tests. The corrosion products were characterized by $\mathrm{X}$-ray diffraction, Mössbauer spectroscopy, and Raman spectroscopy. The specimens were exposed to natural weathering in both atmospheres for nine months. The morphologies of the corrosion products were evaluated using scanning electron microscopy. The main product found was lepidocrocite. Goethite and magnetite were also found on the corroded specimens but in lower concentrations. The results showed that the accelerated test based on the ASTM B117 procedure presented poor correlation with the atmospheric corrosion tests whereas an alternated fog/dry cycle combined with UV radiation exposure provided better correlation.
\end{abstract}

\section{Introduction}

Accelerated corrosion tests such as salt spray are of major interest for a variety of industries due to their ability of providing results more quickly than those obtained from natural weathering, giving support to the development of new alloys and protective coatings. The lack of correlation between the two types of tests, accelerated and natural weathering, however, has been the main drawback of accelerated testing. The development of laboratory tests which can simulate as closely as possible atmospheric effects has strategic significance. Many companies have considerable interest in the evaluation of new products designed to reduce the corrosion process, for example, the painting industry.

Several authors used different accelerated corrosion tests [1-6] and highlighted the importance of alternated fog/dry cycles (Prohesion test) combined with ultraviolet radiation and condensation cycles to improve the correlation between accelerated and natural weathering tests. A continuous salt fog test (ASTM B-117) was related to lack of correlation.

The corrosion products formed on the surface of materials exposed to either natural weathering or accelerated corrosion tests are related to the corrosion mechanisms involved in their formation. The identification of the oxide/hydroxide phases formed during corrosion tests therefore gives information on the correlation between the natural weathering and the laboratory tests as the similarity in the composition of the rust layers may represent similar corrosion mechanisms. In Brazil, the information about the steel corrosion products formed in different atmospheres is still scarce.

Some works in the literature [7-14] give valuable data related to the composition and morphology found in corrosion products of carbon steel specimens exposed to atmospheric conditions. Almeida et al. [15] reported that the initial stages of atmospheric corrosion of carbon steel in both rural and urban atmospheres yield the formation of lepidocrocite 
TABLE 1: Chemical composition of the carbon steel specimens used in this study.

\begin{tabular}{lcccccccc}
\hline Element & $\mathrm{C}$ & $\mathrm{S}$ & $\mathrm{Al}$ & $\mathrm{Cu}$ & $\mathrm{Mn}$ & $\mathrm{P}$ & $\mathrm{Si}$ & $\mathrm{Cr}$ \\
\hline wt.\% & 0.037 & 0.009 & 0.062 & $<0.005$ & 0.27 & 0.02 & 0.01 & $<0.005$ \\
\hline
\end{tabular}

$(\gamma$-FeOOH$)$ and goethite $(\alpha$-FeOOH). In chloride containing environments another form of iron oxyhydroxide, akaganeite $(\beta-\mathrm{FeOOH})$, is frequently found [16-18]. Magnetite $\left(\mathrm{Fe}_{3} \mathrm{O}_{4}\right)$ is also frequently reported in coastal environments $[19,20]$. Lepidocrocite and goethite are reported as the main phases independently of the environment [21,22]. Raman spectroscopy and Mössbauer spectroscopy have been successfully used to characterize the different oxide phases formed on iron based alloys [23-26].

In this work the morphology and composition of the rust formed on carbon steel specimens exposed at two distinct atmospheres (urban and industrial) for nine months and to two accelerated corrosion tests were evaluated. Xray diffraction, Raman spectroscopy, and Mössbauer spectroscopy were used to identify the oxide phases formed during the tests. Scanning electron microscopy (SEM) was used to characterize the morphology of these phases.

\section{Experimental}

2.1. Material. The material tested was carbon steel whose composition is shown in Table 1 . The dimensions of the specimens for atmospheric exposure were $150 \mathrm{~mm} \times 150 \mathrm{~mm}$ and for accelerated testing were $150 \mathrm{~mm} \times 75 \mathrm{~mm}$. Prior to exposure the specimens were degreased with organic solvent and blast cleaned (Sa 2.5 finish).

2.2. Test Sites. The specimens were exposed at two different sites in São Paulo State, Brazil. The first site, called Paula Souza, is located in downtown São Paulo, being typical of urban, polluted atmosphere. The second one at Cubatão is typical of an industrial atmosphere. The atmospheric conditions of both sites are characterized elsewhere [27, 28]. The specimens were exposed for a maximum period of nine months, according to ASTM G 50-76. The corrosion products evaluated in this work were formed during periods of exposure corresponding to 1, 2, 3, 6, and 9 months. For each exposure period, one specimen was used for evaluation of the corrosion products.

2.3. Accelerated Corrosion Tests. Two accelerated corrosion tests were carried out, Test A and Test B. Test A was based on the ASTM 5894-96 standard and included alternating periods of exposure between a Fog/Dry cabinet, using the Prohesion cycle and an UV radiation and condensation cabinet (UVCON cabinet). The Prohesion cycle consisted of $1 \mathrm{~h}$ fog cycle using a solution made of $0.35 \mathrm{wt} . \%\left(\mathrm{NH}_{4}\right)_{2} \mathrm{PO}_{4}$ and 0.05 wt. $\% \mathrm{NaCl}$, alternated with $1 \mathrm{~h}$ dry periods under air stream at $35^{\circ} \mathrm{C}$. In the UVCON cabinet the specimens were exposed during $4 \mathrm{~h}$ periods to UV-A radiation alternated with $4 \mathrm{~h}$ periods of condensation, according to ASTM G53. The specimens were maintained in each cabinet (Fog/Dry cabinet and UVCON) for 7 days and then transferred to the other cabinet. A whole cycle comprised 7 days exposure in each cabinet. The test duration comprised 4 cycles.

The conditions of Test B were 7 days of exposure to salt spray test, according to ASTM B-117, alternated with 7 days of exposure in the UVCON cabinet, using UV-A radiation and condensation periods, according to ASTM G53. A whole cycle consisted of 7 days of exposure in each cabinet. The test duration comprised 4 cycles.

2.4. Characterization of the Corrosion Products. After exposure periods corresponding to $1,2,3,6$, and 9 months, one specimen from each atmospheric site was characterized to identify its corrosion products by Raman spectroscopy, Mössbauer spectroscopy, and X-ray diffractometry. The dimensions of the specimens used for these techniques were of $15 \mathrm{~mm} \times 15 \mathrm{~mm}$.

Raman spectroscopy was undertaken using a Renishaw Raman microscope (System 3000), coupled to an Olympus metallographic microscope and fitted with a CCD detector (Wright, $600 \times 400$ pixels). The specimens were excited with the $632.8 \mathrm{~nm}$ line from an air-cooled He-Ne laser (Spectra Physics, mod. 127). 80x magnification objective lenses were used to focus the laser (ca. $0.4 \mathrm{~mW}$ ) on the samples and to collect the scattered light.

For the specimens exposed to natural weathering, the Mössbauer spectra were taken directly over their surfaces using the scattering geometry. For the specimens exposed to accelerated tests, however, the corrosion products were removed from their surfaces before analysis since they were loose and did not permit a direct analysis over the surface. The spectra on these last specimens were taken using the transmission geometry. The radiation source was cobalt- 57 within a rhodium matrix. All spectra were obtained at room temperature.

The XRD measurements were performed employing a Rigaku ULTIMA-IV diffractometer using $\mathrm{Cu}-\mathrm{K}_{\mathrm{alpha}}$ radiation at $40 \mathrm{kV}$ and $30 \mathrm{~mA}$, scintillation detector, and pyrolytic graphite monocromator, in the $2 \theta$ range from $10^{\circ}$ to $85^{\circ}$, $0.025^{\circ}$ steps, and $4 \mathrm{sec} / \mathrm{step}$ counting time. The phase identifications were performed by comparison to ICDD-PDF Database [29]. The quantitative analyses were performed by Rietveld refinement using GSAS/EXPGUI [30] package. SEM was carried out with XL20 Phillips equipment. The specimens were gold coated prior to analysis.

\section{Results}

3.1. Raman Spectroscopy. All specimens analyzed by means of Raman spectroscopy showed three regions of different colours, yellow, red, and black. Three spectra were obtained for each of these regions, on three different areas: at the center and at each border. A total of nine spectra were obtained for each specimen: three from the yellow, three from the red, and three from the black areas. The results shown are an average for each region of each specimen.

The products identified in the oxide layer of the specimens exposed at both sites (urban and industrial) were lepidocrocite $(\gamma-\mathrm{FeOOH})$, goethite $(\alpha-\mathrm{FeOOH})$, and magnetite 


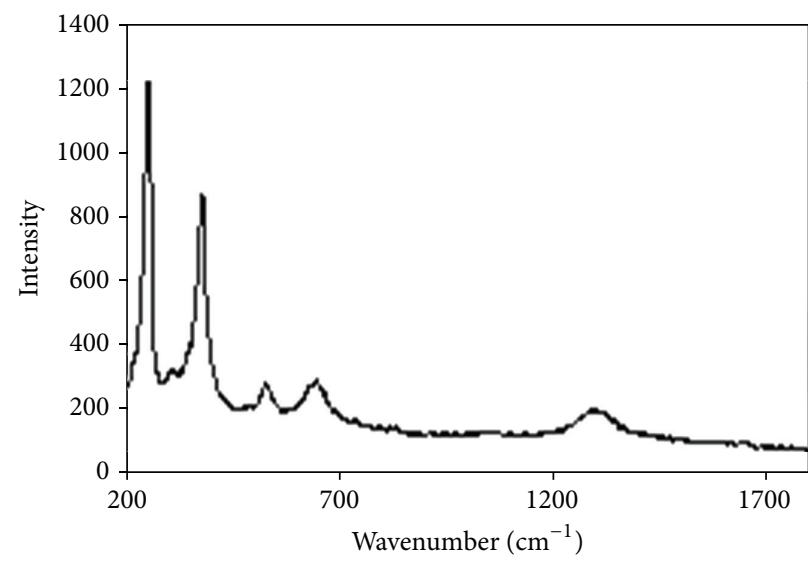

(a)

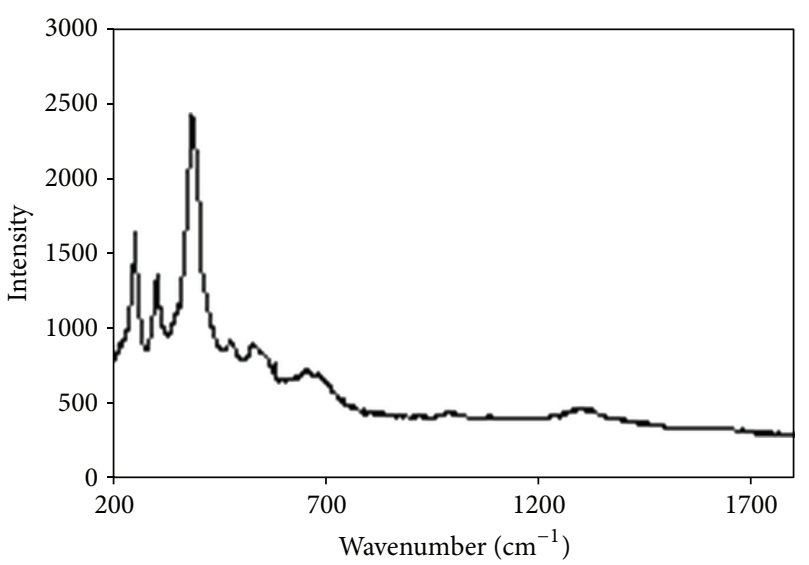

(b)

FIGURE 1: Raman spectra of (a) specimen exposed at Cubatão, for three months, showing peaks characteristic of lepidocrocite ( $\gamma$-FeOOH) and (b) specimen exposed for one month at Paula Souza, showing peaks typical of goethite and lepidocrocite.

$\left(\mathrm{Fe}_{3} \mathrm{O}_{4}\right)$, for all the exposure times. Since the characterization of corrosion products by Raman spectroscopy was performed on a small area (laser spot of ca. $4 \mu \mathrm{m}^{2}$ ), it was not possible to estimate the quantitative contribution of each phase, even probing different regions. However, it was possible to associate the colour of the oxide to a particular phase. It was found that the red oxide showed Raman spectra typical of lepidocrocite $(\gamma-\mathrm{FeOOH})$, with the most intense bands at 245 and $375 \mathrm{~cm}^{-1}[8,9]$. Figure 1(a) shows a spectrum representative of lepidocrocite, for a specimen exposed at Cubatão for three months. The Raman spectra of yellow regions indicated that they correspond to a mixture of lepidocrocite and goethite (most representative bands at 245, $299,385,479$, and $\left.550 \mathrm{~cm}^{-1}[8,9]\right)$. In spite of some band overlap (particularly the $245 \mathrm{~cm}^{-1}$ mode) the spectra allowed an unequivocal differentiation between goethite and lepidocrocite. Figure 1(b) shows a spectrum typical of a yellow region. The black oxides showed Raman spectra with bands of magnetite at 662 and $535 \mathrm{~cm}^{-1}$ together with lepidocrocite and goethite bands (Figure 2). Magnetite is a black oxide [27] and therefore its detection on black areas is not surprising. The spectrum shown in Figure 2 was obtained from black areas on a specimen exposed for two months at Cubatão.

Similar spectra were obtained for all of the exposure times $(1,2,3,6$, and 9 months) independently of the atmospheric sites (Cubatão and Paula Souza), and for the accelerated tests (Test $\mathrm{A}$ and Test $\mathrm{B}$ ).

3.2. Mössbauer Spectroscopy. The fitting procedure of the Mössbauer scattering spectra was difficult for the corrosion products of specimens exposed to natural weathering for the periods evaluated (1, 2, 3, 6, and 9 months). Only a central doublet could be defined for most of the samples. Figure 3 shows an example of a typical spectrum obtained. The doublet was attributed to lepidocrocite in all the samples.

The difficulties of confirming the presence of other phases, which were identified by Raman spectroscopy, such as goethite and magnetite, were due to the poor resolution of

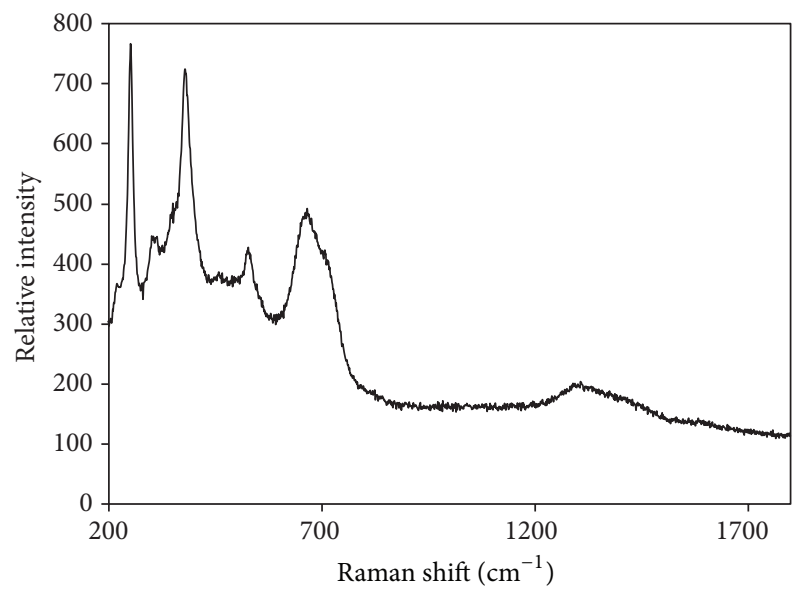

FIGURE 2: Raman spectrum of a specimen exposed for two months at Cubatão, showing peaks typical of magnetite, goethite, and lepidocrocite.

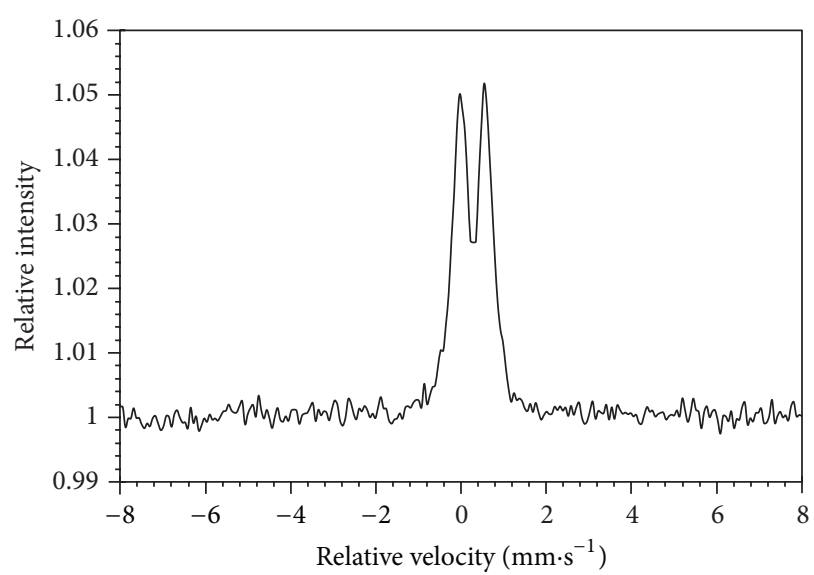

FIgURE 3: Mössbauer spectrum of corrosion products on specimen exposed for 9 months at Cubatão. 
TABLE 2: Mössbauer parameters of the specimens exposed for nine months at Cubatão and Paula Souza and to four cycles of the accelerated tests, $\mathrm{A}$ and $\mathrm{B}$.

\begin{tabular}{|c|c|c|c|c|c|}
\hline & $\mathrm{IS}^{\mathrm{a}} \cdot\left(\mathrm{mm} \cdot \mathrm{s}^{-1}\right)$ & $\mathrm{QS} \cdot\left(\mathrm{mm} \cdot \mathrm{s}^{-1}\right)$ & $\mathrm{Hf}(\mathrm{kOe})$ & $\begin{array}{c}\text { Area occupied } \\
\text { by phase }(\%)\end{array}$ & Phases \\
\hline \multirow{2}{*}{ Cubatão } & 0.39 & 0.62 & - & 86.4 & $\gamma$-FeOOH \\
\hline & 0.22 & -0.18 & 324 & 13.6 & $\alpha-\mathrm{FeOOH}$ \\
\hline Paula Souza & 0.38 & 0.60 & - & 100 & $\gamma$-FeOOH \\
\hline \multirow{4}{*}{ Test A } & 0.36 & 0.59 & - & 12.0 & $\gamma$-FeOOH \\
\hline & 0.37 & -0.24 & 451 & 72.6 & $\mathrm{Fe}_{3} \mathrm{O}_{4}$ \\
\hline & 0.28 & 0.08 & 493 & & \\
\hline & 0.46 & -0.48 & 355 & 15.4 & $\alpha-\mathrm{FeOOH}$ \\
\hline \multirow{4}{*}{ Test B } & 0.39 & 0.62 & - & 22.3 & $\gamma$-FeOOH$/ \beta-\mathrm{FeOOH}$ \\
\hline & 0.58 & -0.26 & 456 & & \\
\hline & 0.29 & 0.06 & 493 & 55.4 & $\mathrm{Fe}_{3} \mathrm{O}_{4}$ \\
\hline & 0.36 & -0.35 & 356 & 22.3 & $\alpha$-FeOOH \\
\hline
\end{tabular}

${ }^{\mathrm{a}}$ The isomer shift values are given related to the $\mathrm{Fe}-\alpha$.

the Mössbauer spectra. The sextets of goethite and magnetite did not fit other results reported in the literature [12-14]. Despite these fitting problems, for some samples the hyperfine parameters (isomer shift, quadrupole splitting, and magnetic hyperfine field) of goethite were in agreement with other works [12-14] and therefore its presence might be presumed. However, magnetite could not be identified in any of the specimens exposed to atmospheric corrosion. Table 2 shows hyperfine parameters of the oxide phases found in the specimens exposed at Cubatão and Paula Souza (9 months of exposure) and to Tests A and $\mathrm{B}$.

Transmission Mössbauer spectra of the specimens exposed to accelerated laboratory tests showed better resolution than the scattering geometry used for specimens exposed to natural weathering. For both tests, Tests A and B, the sextets of goethite and magnetite were well resolved. The hyperfine parameters are shown in Table 2. The main phase found on the corrosion products of specimens exposed to both tests (A and B) was magnetite, followed by goethite and lepidocrocite. The presence of akaganeite was indicated in the specimen exposed to Test B. However, at room temperature akaganeite presents a doublet with hyperfine parameters very similar to those of lepidocrocite [12]. Consequently it is not possible to distinguish between these two phases at room temperature. Figure 4 shows a typical spectrum of corrosion products on specimens submitted to Test A.

3.3. X-Ray Diffraction (XRD). The identification of the corrosion products formed on the specimens exposed to natural weathering and accelerated tests was complemented using XRD analysis. XRD patterns of the specimens exposed at Cubatão and Paula Souza are presented in Figures 5 and 6, respectively. XRD patterns of the specimens submitted to accelerated tests A and B are shown in Figure 7. The phases identified on each specimen were quantified by Rietveld refinement and the results are displayed in Table 3.

Quantitative X-ray analysis indicates that the main corrosion products in Cubatão were lepidocrocite and goethite up to six months of exposure. Magnetite was identified as a minor constituent on the specimen exposed for six months.

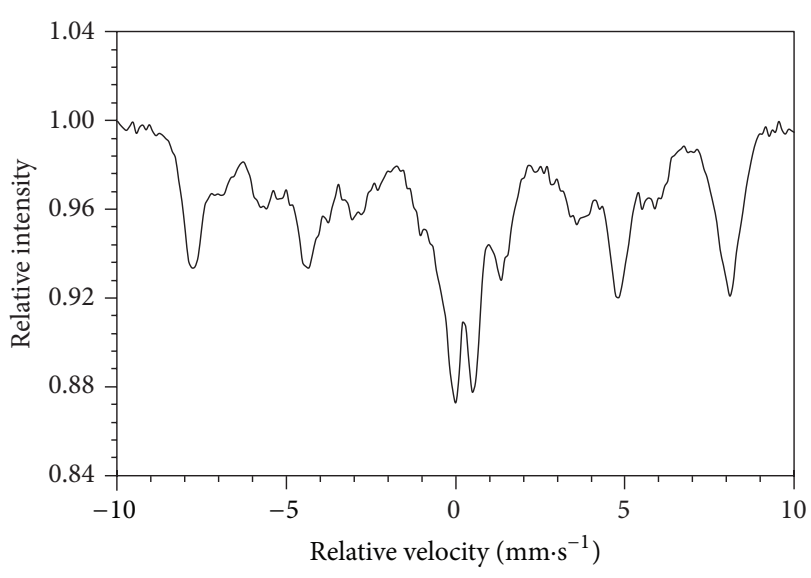

FIGURE 4: Representative Mössbauer spectrum of corrosion products on specimen submitted to accelerated Test A.

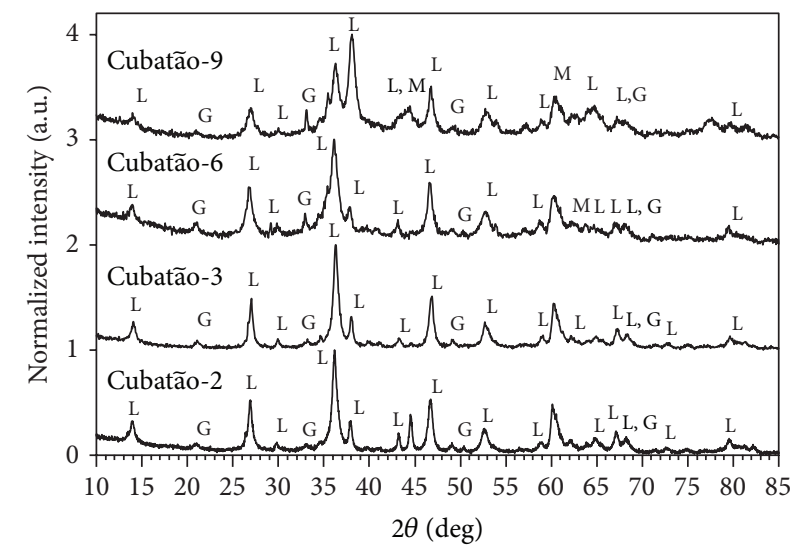

FIGURE 5: XRD patterns of specimens exposed in Cubatão station for different periods. $\mathrm{G}=$ goethite; $\mathrm{L}=$ lepidocrocite; $\mathrm{M}=$ magnetite.

After nine months of exposure, though, it became the major phase on the rust layer. The presence of lepidocrocite and goethite was also observed in Paula Souza. Lepidocrocite was the main phase, followed by goethite. These are the 
TABLE 3: Quantitative analyses of crystal phases determined by Rietveld refinement of XRD data.

\begin{tabular}{|c|c|c|c|c|c|}
\hline \multirow{2}{*}{ Test site } & \multirow{2}{*}{ Exposure time (months) } & \multicolumn{4}{|c|}{ Crystalline phases } \\
\hline & & Lepidocrocite & Goethite & Magnetite & Akaganeite \\
\hline Cubatão & 2 & 58.5 & 41.5 & - & - \\
\hline Cubatão & 3 & 65.7 & 34.3 & - & - \\
\hline Cubatão & 6 & 58.6 & 34.0 & 7.4 & - \\
\hline Cubatão & 9 & 36.5 & 12.6 & 50.9 & - \\
\hline Paula Souza & 2 & 67.2 & 32.8 & - & - \\
\hline Paula Souza & 3 & 60.0 & 40.0 & - & - \\
\hline Paula Souza & 6 & 49.8 & 50.2 & - & - \\
\hline Paula Souza & 9 & 59.4 & 40.6 & - & - \\
\hline Test A & - & 6.6 & 37.6 & 55.8 & - \\
\hline Test B & - & 14.6 & 31.7 & 42.7 & 11.0 \\
\hline
\end{tabular}

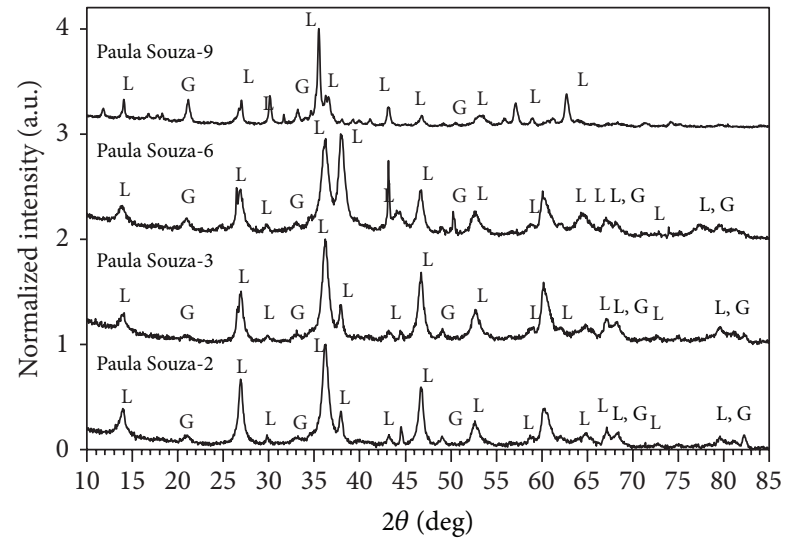

FIGURE 6: XRD patterns of specimens exposed in Paula Souza station for different periods. $\mathrm{G}=$ goethite; $\mathrm{L}=$ lepidocrocite.

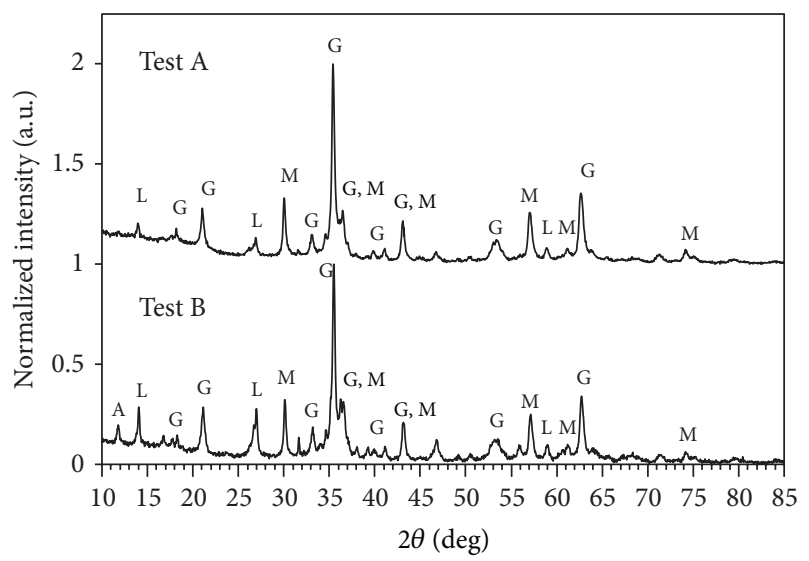

FIGURE 7: XRD patterns of specimens submitted to accelerated tests. $\mathrm{A}=$ akaganeite; $\mathrm{G}$ = goethite; $\mathrm{L}=$ lepidocrocite; $\mathrm{M}=$ magnetite.

main phases on rusts formed on carbon steels during natural weathering [19]. Magnetite was not found by XRD on any of the specimens exposed in Paula Souza. According to Momber [31] magnetite would be the final form of corrosion product on carbon steels, after transformation from lepidocrocite into goethite and, finally, magnetite. The XRD data unequivocally identified magnetite on the specimens exposed for six and nine months at Cubatão, but not at Paula Souza.

The major oxide phase on the specimen submitted to Test A was magnetite, followed by goethite and a smaller amount of lepidocrocite. In Test B these three phases were also found and, additionally, akaganeite was identified. This phase is reported as a typical iron oxide component in marine environments [19]. Hence, its presence was expected on the specimen exposed to Test B. In this respect, the result obtained by Mössbauer spectroscopy (Table 2) could be effectively verified by XRD, confirming the formation of akaganeite on the steel rust after Test $\mathrm{B}$.

\subsection{Scanning Electron Microscopy (SEM)}

3.4.1. Natural Weathering/Atmospheric Corrosion. All specimens exposed to natural weathering at the two sites and observed by SEM showed morphological structures typical of lepidocrocite and goethite. Figure 8 shows a micrograph of a specimen exposed at Cubatão for one month. Cotton ball structures, typical of semicrystalline goethite [29], interconnected by nest like formations were often found on all the specimens.

The micrograph of a specimen exposed for three months to the urban atmosphere is shown in Figure 9. Sandy crystals typical of lepidocrocite $[10,11]$, are frequently found, in agreement with the Mössbauer spectroscopy data which showed that lepidocrocite is the main phase of the oxide layer on these specimens. The magnetite pattern (flat and dark areas, with circular disks [11]) was not found in any of the specimens exposed to natural weathering.

3.4.2. Accelerated Tests. The structures of the corrosion products formed on the specimens exposed to Tests A and B are more crystalline than those on the specimens exposed to atmospheric corrosion. Particularly for the specimens submitted to Test $\mathrm{B}$, the morphologies of the corrosion products presented very sharp structures typical of crystalline goethite [11], as shown in Figure 10(a). Magnetite structure was also observed as illustrated in Figure 10(b). Cotton balls typical of semicrystalline goethite [11] and sandy structures were not found. 


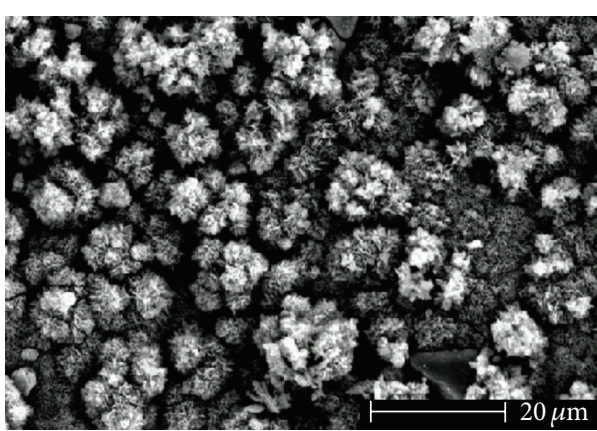

(a)

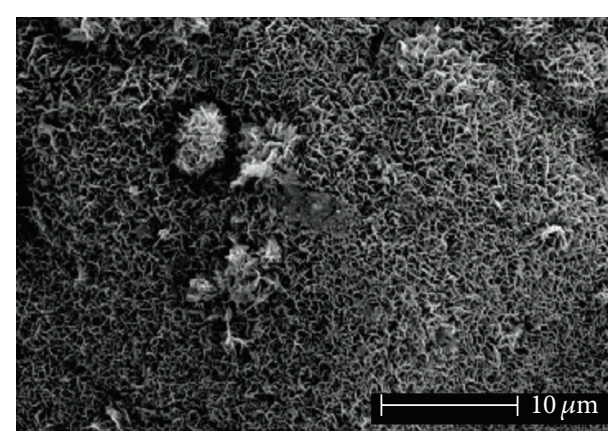

(b)

Figure 8: Micrographs of specimen exposed at Cubatão for one month, showing "cotton ball" structures, (a) and nest formations, interconnecting the cotton balls (b).

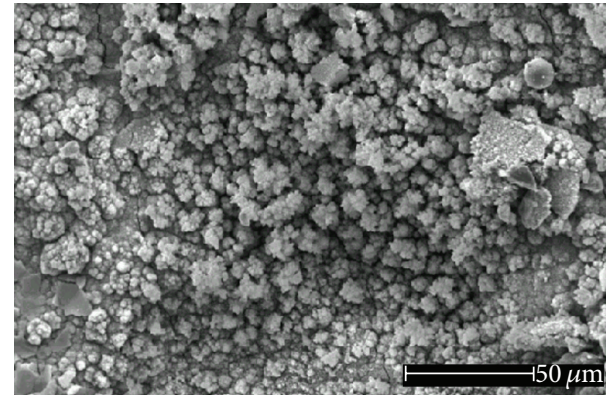

Figure 9: Micrograph showing sandy crystals typical of lepidocrocite.

For both types of specimens, exposed to either Test A or Test B, crystalline structures were observed, although the crystalline structure of specimens exposed to Test A was less marked than that associated with specimens exposed to Test B. Magnetite morphology was not observed. Cotton balls and sandy structures were not seen. Another morphology typical of lepidocrocite, which was also observed on several specimens exposed to atmospheric corrosion, the flowery structure [10] shown in Figure 10(c), was identified.

\section{Discussion}

4.1. Atmospheric Corrosion/Natural Weathering. The Raman spectroscopy results, despite their qualitative character, gave indications about the predominance of lepidocrocite on the specimens exposed to natural weathering. The predominance of lepidocrocite was expected as this oxide phase is usually reported as the initial corrosion product formed on carbon steels [31]. Visual observation of the specimens showed that the red regions, typical of lepidocrocite, were present in much larger proportions than the yellow (goethite) or black (magnetite) regions. The yellow regions occupied a larger area than the black regions. Thus, lepidocrocite was inferred as the major phase in the rust layer, followed by goethite and magnetite.

XRD analyses provided quantitative evidence for the qualitative indications of the Raman spectra. Lepidocrocite and goethite were the only phases identified in the rust layer of the samples exposed in Cubatão for up to three months. Magnetite was identified in the sample exposed for six months. After nine months the amount of magnetite increased significantly. Cubatão station is classified as an industrial atmosphere with reported corrosion rate of $119 \mu \mathrm{m} /$ year and a chloride content of $7.97 \mathrm{mg} / \mathrm{m}^{2}$. day [32]. The formation of magnetite is favored depending on the severity of the atmospheric corrosion process. Some reports point that magnetite is the final form of iron oxide during atmospheric exposure of plain carbon steels and this would be favored in more aggressive environments where the oxidation process is faster [31, 33].

Magnetite was not identified by XRD in the samples exposed in Paula Souza station, regardless of the exposure time. The qualitative Raman spectra shown in Section 3.1 have indicated the presence of magnetite in these specimens. It is likely that the volume fraction of magnetite formed during the nine months of atmospheric corrosion was not sufficient to be detected by XRD. However, when the Raman laser was focused on the black regions of the surface rust layer on these specimens, then magnetite could be locally identified. Moreover, the corrosion rate of plain carbon steel in Paula Souza is reported to be only $15.4 \mu \mathrm{m}$ /year whereas it is $119 \mu \mathrm{m} /$ year in Cubatão. Thus, the formation of magnetite would proceed slowly in Paula Souza due to a slower oxidation process. It is also interesting to note that the ration goethite/lepidocrocite is higher for the specimens exposed in Paula Souza station than for those exposed in Cubatão station. According to the literature, for transformation of lepidocrocite into goethite is favored in atmospheres with $\mathrm{SO}_{2}$ contamination [34]. The $\mathrm{SO}_{2}$ content is reported to be higher in Paula Souza than in Cubatão [27, 32], thus supporting the quantitative findings obtained by XRD.

SEM micrographs showed morphologies typical of lepidocrocite (sandy and flowery structures) and goethite (cotton balls) as the major structures for all of the samples observed confirming the Raman spectroscopy results. Morphology typical of magnetite (flat and dark areas with circular disks [9]) was not identified by SEM images. This can be attributed to two major aspects. The first one is that the formation of magnetite can occur from the inner to the outer rust layers, as the transformation of lepidocrocite into magnetite is favored when the oxygen supply is low. Thus, the top surface analysis 


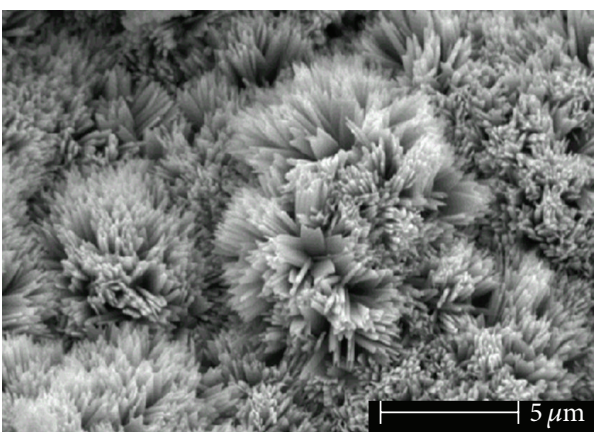

(a)

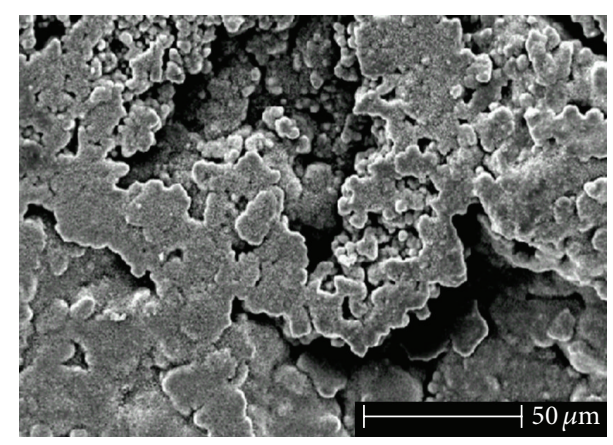

(b)

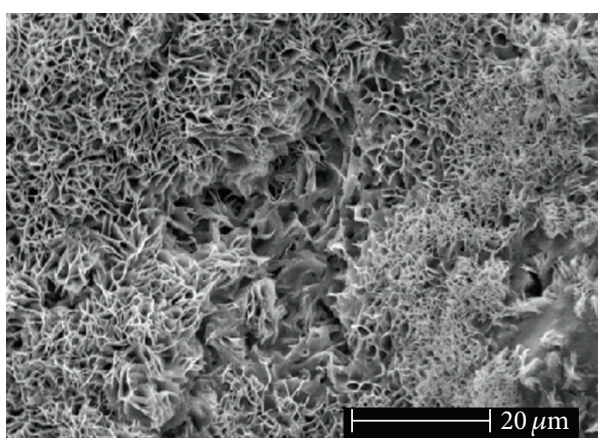

(c)

FIGURE 10: Micrographs showing (a) sharp structures (crystalline goethite); (b) flatten and dark disks of magnetite; and (c) flowery structures typical of lepidocrocite.

by SEM would not detect typical morphologies of magnetite, even when it is present into the bulk oxide film. The second one is that for some specimens the amount of magnetite was low and could not be detected by XRD. Hence, SEM analyses could not identify typical morphologies of magnetite on these specimens.

Mössbauer analysis showed only the presence of lepidocrocite for most samples. Problems with resolution of the Mössbauer spectra were responsible for the incomplete results obtained by this technique. This result, however, confirmed the Raman spectroscopy data and XRD analyses which showed lepidocrocite as the main phase for all samples exposed to natural weathering in Paula Souza and in Cubatão up to three months. However, when the amount of goethite and magnetite is considered, the Mössbauer analyses performed at room temperature did not provide reliable information.

4.2. Accelerated Tests. The characterization of the corrosion products on the specimens exposed to Test A (Prohesion cycle alternated with UV-A radiation and condensation cycles) showed that their rust layer composition was very similar to that of specimens exposed to natural weathering, at either urban or industrial atmospheres. Raman spectroscopy results showed lepidocrocite as the major product of the rust layer followed by goethite and magnetite.

SEM micrographs showed structures typical of goethite and lepidocrocite. However, few differences were found between the morphologies of the corrosion products produced by natural weathering and accelerated tests. For specimens exposed to the accelerated tests, the morphologies of the corrosion products were sharp and porous and with high regularity, revealing high crystallinity. On the other hand, the corrosion products of the specimens submitted to natural weathering showed low porosity, sharpness, or regularity. Even though the rust phases and their intensities were similar to the two types of tests, the different morphologies are probably due to the aggressiveness of Test A conditions compared to the atmospheric exposure.

Mössbauer results showed the predominance of magnetite with small quantities of lepidocrocite in the corrosion products of specimens exposed to Test A. Nevertheless, as described earlier, the Raman spectroscopy data indicated lepidocrocite as the major phase in the corrosion products, with minor quantities of goethite and magnetite. The difference of the relative intensity of each phase found for the results obtained by Mössbauer spectroscopy and Raman spectra may be related to differences in sample preparation. For Raman spectroscopy the analysis was carried out directly over the surface of the specimens without scraping the corrosion products. For Mössbauer spectroscopy, the corrosion product was scraped off the surface and the powder obtained was submitted to analysis. Therefore, the results are representative not only of the surface but also of the inner layers. Magnetite is generally formed at the oxide/metal interface [11]. Thus, its predominance in the Mössbauer spectrum is possibly due to this. This corroborates the XRD data (Table 3) which also revealed the predominance of magnetite in the specimens exposed to Test A and was also carried out with the scraped corrosion product and not at the surface of the specimen. 
The analysis of corrosion products on specimens submitted to Test B (salt spray test alternated with UV-A radiation and condensation cycles) showed different results from those of the specimens exposed to natural weathering or to Test A. For specimens exposed to Test B, Raman analyses showed magnetite as the main phase. Raman spectra of these specimens revealed black regions (typical of magnetite) in larger proportions than yellow (goethite) or red regions (lepidocrocite). Mössbauer analysis also suggested that akaganeite is present on the corrosion product, and this phase was not present on the specimens exposed to natural weathering, either at Cubatão or at Paula Souza or even to Test A. As akaganeite is typical of atmospheres with high chloride contents [11], its presence on specimens exposed to Test B was not surprising since the salt spray cycle consists of a continuous fog of $\mathrm{NaCl} 5 \mathrm{wt}$.\% solution. According to the literature [20], magnetite is typical of aggressive atmospheres. XRD data confirmed the presence of akaganeite on the specimens exposed to Test B (Table 3).

XRD analysis and Mössbauer spectroscopy data provided quantitative evidence that magnetite is the dominant phase in the specimens exposed to Test B and that akaganeite is also formed probably due to contact of the steel surface with the chloride ions in salt spray fog. This result has no correlation with the atmospheric corrosion tests carried out either in Paula Souza station (urban atmosphere) or in Cubatão station (industrial atmosphere). Notwithstanding, the results obtained from the specimens exposed to Test A point to the predominance of magnetite (Table 3 ) without signs of akaganeite. This behavior is similar to that observed for the specimens submitted to natural weathering. However, it is important to bear in mind that the amount of lepidocrocite is smaller in the specimens submitted to Test A (Table 3) than that obtained for the atmospheric exposure regardless of the exposure time. In this respect, it is possible to infer that the experimental conditions of Test A are more suitable to simulate natural weathering. Nevertheless, the experimental conditions are more aggressive than for the atmospheric exposure, as indicated by the smaller amount of lepidocrocite.

Morphology typical of magnetite was identified by means of SEM on several areas of the sample observed by SEM (Figure 10(b)), confirming the predominance of this phase. SEM micrographs also showed structures typical of crystalline goethite (Figure 10(a)). There were no signs of lepidocrocite structures. The morphology of the corrosion products on specimens exposed to Test B was more crystalline and showed sharper and more regular formations than those on the specimens submitted to Test A, indicating the superior aggressiveness of Test $\mathrm{B}$.

\section{Conclusions}

The composition of the rust layer and the intensities of each phase were similar to the specimens exposed to urban or industrial atmospheres (Paula Souza and Cubatão, resp.). The main phases in their corrosion products were lepidocrocite, goethite, and magnetite. Raman spectroscopy provided qualitative results that allowed the association between the oxide colour (red, yellow, or black) and its composition. Mössbauer analysis presented some resolution concerns but allowed qualitatively identifying the main oxide phases present on each sample. XRD analysis provided quantitative information on the composition of the corrosion products. Lepidocrocite was the major phase in rust layer of the specimens exposed in Cubatão station up to six months whereas magnetite was the main constituent after nine months of exposure. Lepidocrocite was the main phase in the specimens exposed in the less aggressive atmosphere of Paula Souza station regardless of the exposure time. Akaganeite was identified in the corrosion products of the specimens submitted to Test B.

The accelerated test that included the Prohesion cycle (Test A) presented better correlation with natural weathering results. On the other hand, the accelerated test that involved the salt spray cycle (Test B) was more aggressive and showed poor correlation with atmospheric corrosion tests.

\section{Conflict of Interests}

The authors declare that there is no conflict of interests regarding the publication of this paper.

\section{Acknowledgments}

The authors are grateful to FAPESP (Sao Paulo State Foundation for Research Support) and to CNPq (National Council of Research and Development) for providing financial support to this work. Thanks are also due to COSIPA (Companhia Siderurgica Paulista) for providing the specimens used in this study. Dr. Dalva Lúcia Araújo de Faria (University of São Paulo-IQUSP) is acknowledged for the Raman measurements. This work is dedicated to the loving memory of Dr. Hercílio R. Rechenberg who greatly contributed to the analysis of Mössbauer spectroscopy results.

\section{References}

[1] M. P. Varma, J. L. Khanna, and V. Murlidharan, "Evaluation of durability characteristics of epoxy poly urethane painting system through QUV apparatus," in Proceedings International Conference on Corrosion (CONCORN '97), Mumbai, India, December 1997.

[2] C.-C. Lin and C.-X. Wang, "Correlation between accelerated corrosion tests and atmospheric corrosion tests on steel," Journal of Applied Electrochemistry, vol. 35, no. 9, pp. 837-843, 2005.

[3] U. Steinsmo, "Test Methods for evaluation of coating systems," in Proceedings of the 10th NITO-NKF Anniversary Conference: Corrosion and Materials Offshore, Oslo, Norway, 1994.

[4] B. Boelen, B. Schmitz, J. Defourny, and F. Blekkenhorst, "A literature survey on the development of an accelerated laboratory test method for atmospheric corrosion of precoated steel products," Corrosion Science, vol. 34, no. 11, pp. 1923-1931, 1993.

[5] C. H. Simpson, C. J. Ray, and B. S. Skerry, "Accelerated corrosion testing of industrial maintenance paints using a cyclic corrosion weathering method," Journal of Protective Coatings \& Linings, vol. 8, no. 5, pp. 27-36, 1991.

[6] J. Andrews, F. Anwari, B. J. Carlozzo et al., "Correlation of accelerated exposure testing and exterior exposure sites," Journal of Coatings Technology, vol. 66, no. 837, pp. 49-67, 1994. 
[7] M. Criado, S. Martínez-Ramirez, S. Fajardo, P. P. Gõmez, and J. M. Bastidas, "Corrosion rate and corrosion product characterisation using Raman spectroscopy for steel embedded in chloride polluted fly ash mortar," Materials and Corrosion, vol. 64, no. 5, pp. 372-380, 2013.

[8] D. L. A. de Faria, S. Venâncio Silva, and M. T. de Oliveira, "Raman microspectroscopy of some iron oxides and oxyhydroxides," Journal of Raman Spectroscopy, vol. 28, no. 11, pp. 873878, 1997.

[9] R. J. Thibeau, C. W. Brown, and R. H. Heidersbach, "Raman spectra of possible corrosion products of iron," Applied Spectroscopy, vol. 32, no. 6, pp. 532-535, 1978.

[10] M. Ronda, J. Gómez, P. Leiva et al., "Caracterización de los productos de corrosión del acero dulce expuesto en un ambiente industrial-costero durante un año," Corrosão e Proteção de Materiais, vol. 16, pp. 30-34, 1997.

[11] A. Raman, S. Nasrazadani, and L. Sharma, "Morphology of rust phases formed on weathering steels in various laboratory corrosion tests," Metallography, vol. 22, no. 1, pp. 79-96, 1989.

[12] S. J. Oh, D. C. Cook, and H. E. Townsend, "Characterization of iron oxides commonly formed as corrosion products on steel," Hyperfine Interactions, vol. 112, no. 1-4, pp. 59-65, 1998.

[13] A. Rincón, O. T. de Rincón, C. Haces, N. R. Furet, and F. Corvo, "Evaluation of steel corrosion products in tropical climates," Corrosion, vol. 53, no. 11, pp. 835-841, 1997.

[14] S. J. Oh, D. C. Cook, and H. E. Townsend, "Study of the protective layer formed on steels," Hyperfine Interactions, vol. C3, pp. 84-87, 1998.

[15] E. Almeida, M. Morcillo, B. Rosales, and M. Marrocos, "Atmospheric corrosion of mild steel part I-rural and urban atmospheres," Materials and Corrosion, vol. 51, no. 12, pp. 859-864, 2000.

[16] T. Nishimura, H. Katayama, K. Noda, and T. Kodama, "Electrochemical behavior of rust formed on carbon steel in a wet/dry environment containing chloride ions," Corrosion, vol. 56, no. 9, pp. 935-941, 2000.

[17] T. Kamimura, S. Hara, H. Miyuki, M. Yamashita, and H. Uchida, "Composition and protective ability of rust layer formed on weathering steel exposed to various environments," Corrosion Science, vol. 48, no. 9, pp. 2799-2812, 2006.

[18] Y. Ma, Y. Li, and F. Wang, "Corrosion of low carbon steel in atmospheric environments of different chloride content," Corrosion Science, vol. 51, no. 5, pp. 997-1006, 2009.

[19] J. G. Castaño, C. A. Botero, A. H. Restrepo, E. A. Agudelo, E. Correa, and F. Echeverría, "Atmospheric corrosion of carbon steel in Colombia," Corrosion Science, vol. 52, no. 1, pp. 216-223, 2010.

[20] S. Syed, "Atmospheric corrosion of hot and cold rolled carbon steel under field exposure in Saudi Arabia," Corrosion Science, vol. 50, no. 6, pp. 1779-1784, 2008.

[21] S. Syed, "Atmospheric corrosion of carbon steel at marine sites in Saudi Arabia," Materials and Corrosion, vol. 61, no. 3, pp. 238244, 2010.

[22] K. V. S. Ramana, S. Kaliappan, N. Ramanathan, and V. Kavitha, "Characterization of rust phases formed on low carbon steel exposed to natural marine environment of Chennai harbourSouth India," Materials and Corrosion, vol. 58, no. 11, pp. 873880, 2007.

[23] E. Hazan, Y. Sadia, and Y. Gelbstein, "Characterization of AISI 4340 corrosion products using Raman spectroscopy," Corrosion Science, vol. 74, pp. 414-418, 2013.
[24] X. Zhang, K. Xiao, C. Dong, J. Wu, X. Li, and Y. Huang, "In situ Raman spectroscopy study of corrosion products on the surface of carbon steel in solution containing $\mathrm{Cl}^{-}$and $\mathrm{SO}_{4}{ }^{2-}$," Engineering Failure Analysis, vol. 18, no. 8, pp. 1981-1989, 2011.

[25] J. A. Jaén, J. Iglesias, and C. Hernández, "Analysis of short-term steel corrosion products formed in tropical marine environments of Panamá," International Journal of Corrosion, vol. 2012, Article ID 162729, 11 pages, 2012.

[26] A. V. Ramesh Kumar, R. K. Nigam, S. S. Monga, and G. N. Mathur, "Effect of inhibitors on the nature of corrosion products of mild steel by Mossbauer and FTIR spectroscopy," AntiCorrosion Methods and Materials, vol. 49, no. 2, pp. 111-117, 2002.

[27] M. Morcillo, E. Almeida, B. Rosales, J. Uruchurtu, and M. Marrocos, Corrosion y Protección de Metales en las Atmo'sferas de Iberoamérica. Parte I-Mapas de Iberoamérica de Corrosividad Atmosférica (Proyecto MICAT, XV.1/CYTED), CYTED, Madrid, Spain, 1998.

[28] M. Morcillo, B. Chico, D. de la Fuente, and J. Simancas, "Looking back on contributions in the field of atmospheric corrosion offered by the MICAT ibero-american testing network," International Journal of Corrosion, vol. 2012, Article ID 824365, 24 pages, 2012.

[29] A. C. Larson and R. B. von Dreele, "General Structure Analysis System (GSAS)," Los Alamos National Laboratory Report LAUR 86-748, 2000.

[30] B. H. Toby, "EXPGUI, a graphical user interface for GSAS," Journal of Applied Crystallography, vol. 34, no. 2, pp. 210-213, 2001.

[31] A. Momber, "Colour-based assessment of atmospheric corrosion products, namely of flash rust, on steel," Materials and Corrosion, vol. 63, no. 4, pp. 333-342, 2012.

[32] Z. Panossian, N. L. Almeida, and F. J. Seixas, Corrosão Atmosférica de Metais no Estado de São Paulo, Bullettin 57, Instituto de Pesquisas Tecnológicas (IPT), São Paulo, Brazil, 1991 (Portuguese).

[33] A. Soare and C. Mandravel, "Nature of the corrosion products formed on carbon steel under marine atmosphere environment investigated by vibration spectroscopy," Revista de Chimie, vol. 61, no. 4, pp. 383-386, 2010.

[34] Z. Wang, J. Liu, L. Wu, R. Han, and Y. Sun, "Study of the corrosion behavior of weathering steels in atmospheric environments," Corrosion Science, vol. 67, pp. 1-10, 2013. 

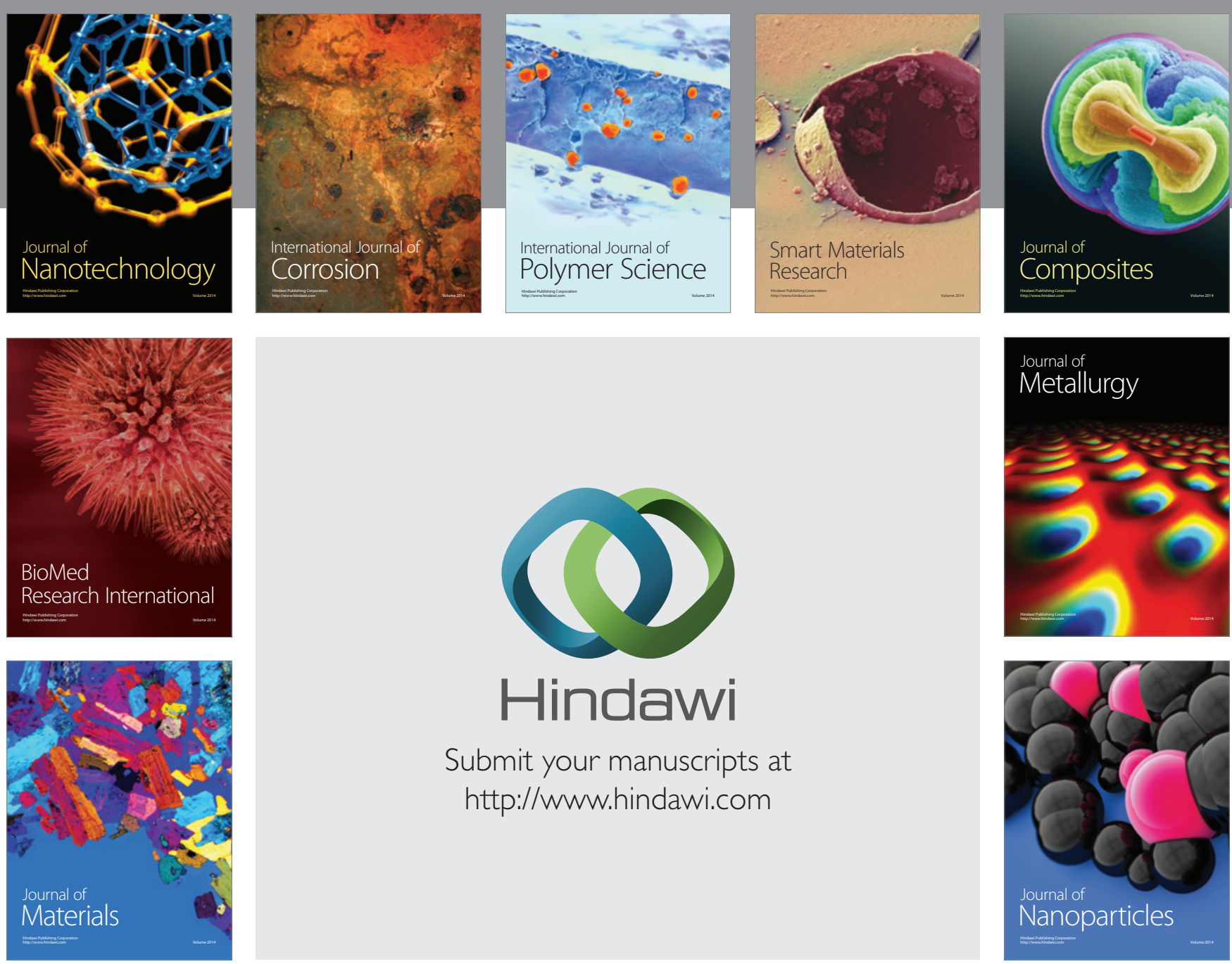

Submit your manuscripts at http://www.hindawi.com
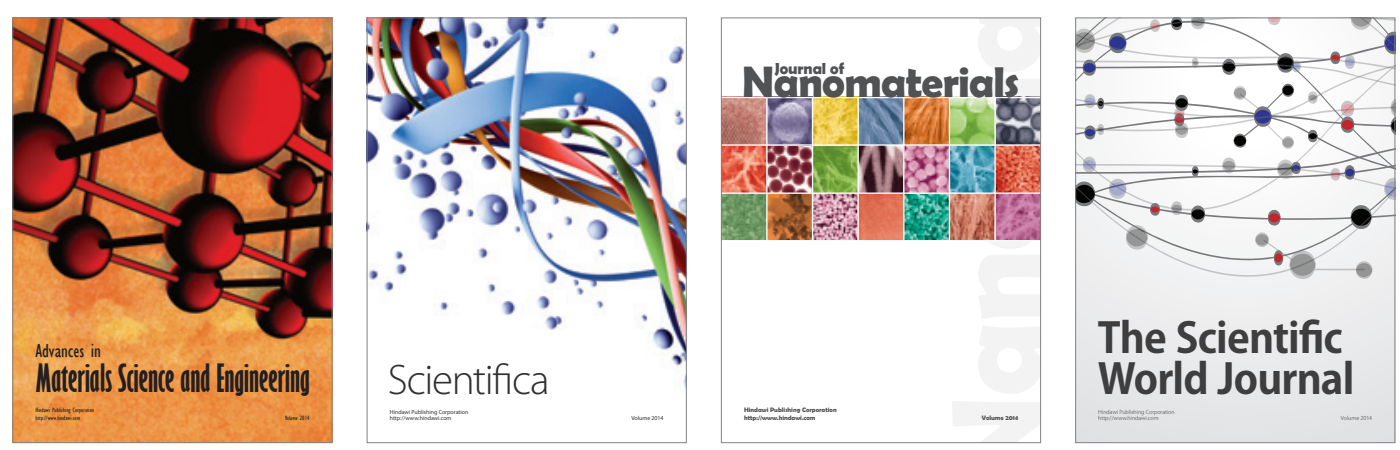

\section{The Scientific World Journal}
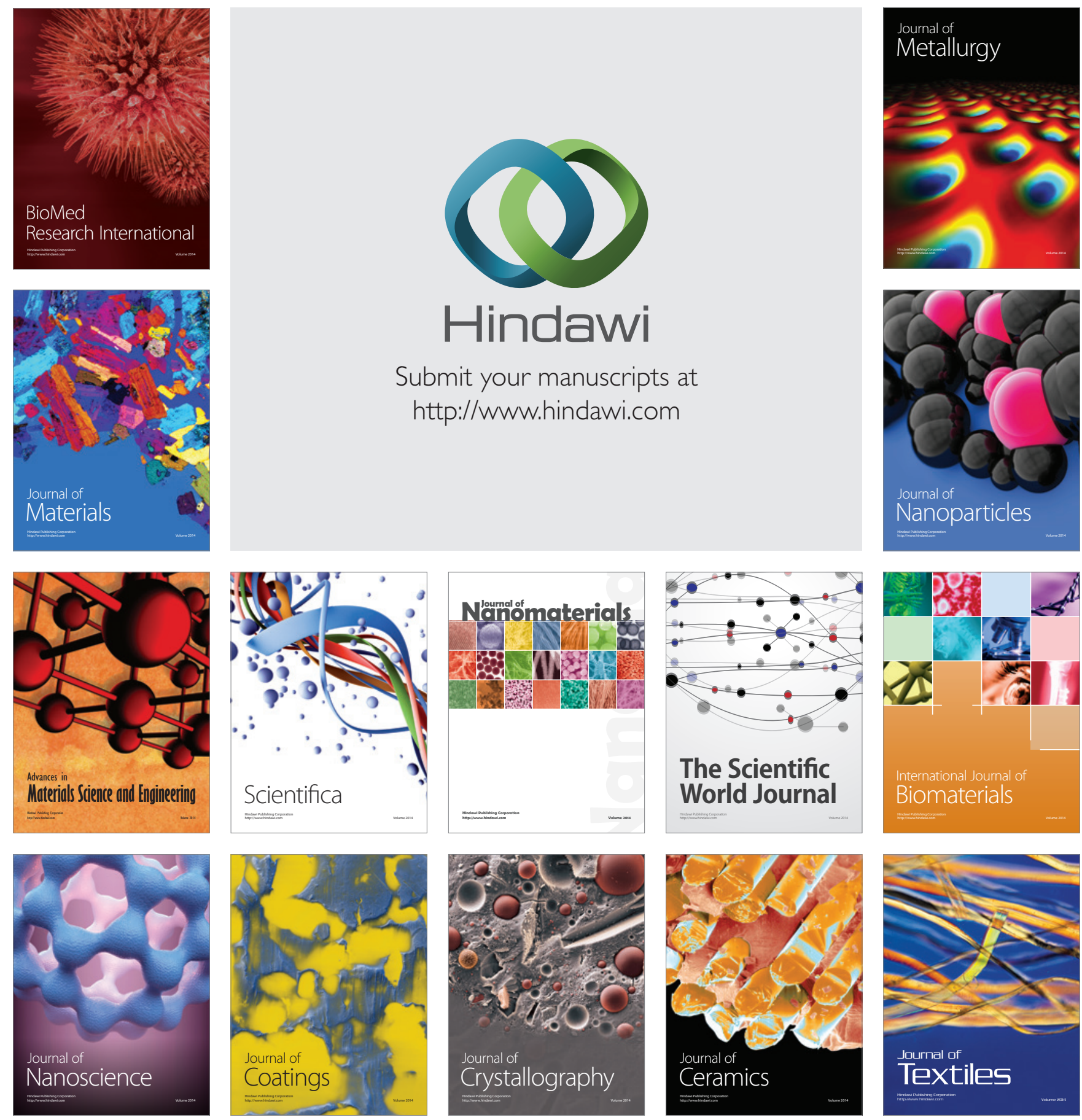